\title{
4
}

\section{Wildlife, wilderness and the politics of alternative land use: an Australian ethnography}

\author{
Adrian Peace
}

\begin{abstract}
As long-established (settler) farming practices become increasingly unviable in Australia's marginal areas, it is widely argued in governmental and other circles that the extension of wilderness areas that are then populated with native wildlife should be actively encouraged. From a developmentalist perspective, this policy is considered to offer up a number of seemingly incontestable benefits: alleviating the pressure on environmentally marginal areas, creating new employment opportunities, consolidating national biodiversity, and so on. From an anthropological vantage point, however, the prospects generated by this kind of development are by no means so clear cut. In the past five years or so, a state-supported initiative to reintroduce a particular species of wallaby to Innes National Park at the foot of Yorke Peninsula, South Australia, has generated a political conflict that raises a number of salient questions about this kind of alternative rural development and its relation to conventional agriculture. This chapter is based on ethnographic research conducted in 2005 and explores the significance of the conflict from academic and policy vantage points.
\end{abstract}

\section{Introduction}

The review and reorganisation of long-established settler land-use practices is going to be one of the more urgent and positive outcomes of the current Australian drought and the wider climatic changes of which it is a significant part. While it has taken not just an agricultural crisis but a societal one to bring the situation about, even the short to mid-term prospects of intensive farming in marginal locations are already under review from agricultural organisations, governmental bodies, environmental agencies and related policy-oriented institutions. Inasmuch as the sheer sustainability of settler agriculture in marginal areas is the subject of review and debate, a range of future land-use practices will increasingly become the focus of regional and national political discourse. 
The proposal of this chapter is that anthropology's contribution to this debate is to spell out to decision makers and, more importantly, to those who have decisions imposed on them what are the likely difficulties and hazards of embarking on certain types of rural reform by detailing relevant case studies of recent provenance. I argue that anthropology can provide salutary warnings about rural reforms that appear, at first sight, to be heading in the right kind of environmental direction, but, in the event, encounter a number of hidden and substantial obstacles that are best explored through the tightly focused ethnographic work that still characterises the discipline. In this regard, a major initiative in the past five years to reintroduce an extinct wallaby subspecies to a national park in South Australia becomes an instructive case study.

As settler agriculture in marginal rural areas becomes increasingly non-viable, so the prospect of private land being bought up by the State and transformed or incorporated into national parks and wilderness areas is increasingly mooted, not least because there are many wholesale and piecemeal precedents for doing so in most Australian states. From a diversity of policy-oriented institutions and agencies, the idea that such areas be allowed to 'revert to nature', to 'let nature take its course' or to 'become wilderness once again', seems by many to be an attractive prospect. It is variously argued that it will lead to reduced pressure on scarce water resources, greater landscape diversity, a stay on excessive fertiliser usage and new employment opportunities through tourism. Above all, the strategy can be sold on the strength of preserving and enhancing regional biodiversity since the reintroduction of original flora and fauna is always integral to this kind of rural reform. Bringing back trees and shrubs to places where they once were and restoring mammals and birds to localities from which they have long been extinct become appealing prospects to politicians and public servants, to conservation scientists and environmental advisors, who are variously able to acquire political kudos and cultural capital from their public implementation.

In Australia, we can expect a proliferation of proposals on these lines in the near future. The mantra of biodiversification alone will ensure this to be the case as formal reactions to climate change are promulgated by the political elite before elections, by industrial managers as they spruce up their environmental credentials and by state-based environmental agencies as they consolidate their command over official environmental discourse. It is the response from below that promises to be more unpredictable, for local populations weigh up a wide range of economic and social factors when specific proposals for the rural future are imposed on them from above. It is this array of folk considerations - by no means all of them specifically about land use-that can be detailed by ethnographic inquiry. This is the prospect in principle that is open to anthropological research. In practice, how local farmers and their families respond to a conservation initiative to restore an extinct wallaby species to their rural area is what we are immediately concerned with. 


\section{The proposal from above}

It was the conservationist concern with the promotion of biodiversification that ensured that the tammar wallaby relocation project had a lot going for it from the outset. Especially in South Australian conservation circles, it was well known that the mainland tammar subspecies had been eradicated sometime during the 1930s when farmers and government officials had designated it a rural pest. What was not known until their presence there was rediscovered by a research team of CSIRO scientists in Canberra was that the same subspecies had thrived on a small island in New Zealand, to which a small number had been transported in the 1860s.

The publication of a research paper (Poole et al. 1991, later detailed by Taylor and Cooper 1999 and Taylor et al. 1999) on this unexpected finding more or less coincided with protection of the continent's biodiversity becoming central to the Commonwealth's environmental policy. Designated wilderness areas were specified as appropriate locations for the protection of biodiversity to be established and managed, and this emphatically included the reintroduction of lost species. It became part of the Federal 1996 Action Plan for Australian Marsupials and Monotremes to relocate the tammar wallaby back in its original habitat (Maxwell et al. 1996). From there, the proposal progressed to being enshrined in the Commonwealth's Environment Protection and Biodiversity Conservation Act 1999 (EPBC Act).

The mainland tammar wallaby was the only animal subspecies specified for salvage under the EPBC Act and so, not all that surprisingly, not only the conservation scientists in South Australia's Department of Environment and Heritage (DEH) but the state's leading politicians, including the Minister for the Environment and the Premier, saw substantial opportunities and benefits in this potentially high-profile contribution to preserving the continent's biodiversity. There was an immediate downside that had to be addressed with some urgency. For a second time in its recent history, the tammar had been officially declared a pest due to be eradicated, but on this occasion it was to be exterminated from Kawau Island at the behest of New Zealand's leading environmental authority. It was therefore necessary to transport a breeding population to South Australia as soon as possible. This was to be executed by a small and dedicated network of government scientists in the $\mathrm{DEH}^{\prime}$ s Science and Conservation Directorate.

Before the tammars' return home, as it was increasingly referred to, conservation scientists had chosen the relatively small Innes National Park (9322 hectares) at the foot of Yorke Peninsula as their final destination. It was a location that more than lived up to the stereotype of a wilderness area; it seemed particularly suited to the reintroduction of its original wildlife after more than half a century's absence. Since it was known to be part of the subspecies' mainland habitat on the lower Yorke Peninsula-albeit a habitat greatly transformed in the 
intervening period, of course - this was where the tammars would be considered properly in place once again. It was also especially appropriate, at least on paper, to the larger ambitions of the conservation scientists who proposed to eventually spread the subspecies across the peninsula, because the tammars would be able to migrate north and east from the national park through 'natural corridors' of parcels of privately owned land already set aside for conservation. Additionally, a second release site would be established elsewhere on the peninsula so that a minimum of two 500-strong tammar colonies would be achieved. At this point, under the EPBC Act, the tammar wallaby subspecies would be relieved of its current status of 'extinct in the wild' and considered a viable population that had returned to its natural habitat.

This conservation project was therefore an ambitious one aimed at making a significant contribution to regional biodiversity, not least because it would generate a good deal of new scientific knowledge over a number of years. From the moment they arrived in South Australia, the breeding population was to be closely monitored; the animals were to be kept in captivity in the regional zoological pack for quarantine and veterinary purposes. They were then to be subject to a strictly controlled breeding program that would maximise their reproductive capacity by using a different subspecies of readily available wallaby as surrogate mothers. Once released in Innes National Park, all animals were to be fitted with radio collars emitting signals that would be picked up by mobile tracking towers built specifically for use in park conditions. Finally, from time to time, tammars released from captivity into the wild, or born in it, would be captured in order to monitor their weight, determine their gender, assess their health and reproductive condition, and so on, along with the prime considerations of detailing where they were migrating to and in what numbers.

Since the relocation project was going to be a costly endeavour, the conservation science behind it was carefully spelled out from the beginning in submissions for financial support; to some of this, I will return below. What was not addressed in anything like the same detail were its social and cultural aspects, despite the obvious fact that the project's success hinged on the tammars moving out of the park wilderness and onto the intensely cultivated agricultural land that dominated the whole peninsula. It would be fair to say that, because the biodiversity credentials of the relocation project were so compelling, it was assumed that if any major questions were raised by the local people, they could be dealt with. At the least, the social and cultural impacts of the project were sparsely attended to in contrast with the depth of the scientific investment.

It therefore came as something of a surprise when, as soon as information about the project leaked out, the DEH officials found they had a major problem on their hands. Despite having intended a careful, public relations-controlled release of information to the general public, word got out as a result of a park ranger 
ill-advisedly mentioning the project to a young local farmer whose family property shared a long boundary with Innes National Park and would likely be the tammars' first staging point once they moved off-park. The farmer and his father were instantly alarmed at the prospect of 'the wallaby pest' among their grain crops and, as news spread through customary gossip channels, so too were their immediate neighbours and other farm families further afield. Before too long, the media also picked up on the story, and the first headline on the wallabies' return from New Zealand in South Australia's sole daily newspaper read: 'We'll take the "pest" nobody else wants' (The Advertiser, 13 September 2003).

\section{Conservation science versus commonsense knowledge}

For the next 18 months or so, the conflict that developed between the DEH and its conservation scientists on the one hand, and the local people of lower Yorke Peninsula on the other, turned on the plausibility of the former's natural science versus the validity of the latter's local knowledge. Although there were multiple aspects to the relocation, the critical issue became to what extent the size and the spread of the wallaby population once established could be controlled by a scientifically modelled manipulation of the fox population, which was already in place. From this point onwards, the state government scientists from the city aimed to persuade the farm population on the peninsula that their worst fears of a wildlife invasion, which could threaten their rural way of life, were ill founded.

To say that this official pitch would prove an uphill struggle would be an understatement because: first, this exercise in persuasion emanated from the state capital; second, it came from a government body; and third, it was parlayed to the periphery by professional scientists. On all three counts, local farmers and their families were inclined from the outset to be circumspect and cynical at best, suspicious and dismissive at worst. The idea of a shifting boundary of foxes, a pest with which they were extremely familiar, being able to control an encroaching invasion of tammars, a pest with which they had no prior acquaintance, consistently ran counter to the local knowledge and commonsense on which rural folk prided themselves.

The central focus of debate quickly became the Draft Translocation Proposal: Reintroduction of mainland SA tammar wallabies to Innes National Park, a substantial document on which the conservation scientists had spent a great deal of time and effort. One of the more intriguing (and never quite explained) aspects of this and similar projects was that it did not have to be subject to an environmental impact statement. In lieu of this, the draft proposal could almost pass muster, since it provided a reasonably thorough introduction to the project's background, the selection of the release site, the acquisition, transportation and quarantining of the breeding population, through to the circumstances under 
which the tammars would be released, monitored and managed in the wild. It also specified the criteria for the project's success, as well as its short-term budget.

Undoubtedly the key section of the draft proposal was entitled 'Population management' and it was replete with scientific detail. The section was devoted to demonstrating how it was possible to scientifically model the rate at which the tammar population could be expected to increase, once it gained a foothold in the park wilderness. Superimposed on these data was the likely pattern of fox predation on the tammars, which could be manipulated through baiting practices undertaken by local farmers and/or contract pest controllers with experience of the region. Five possible scenarios were detailed in intricate graphs, which, at least to a layman, were not immediately comprehensible-but the major claims being made were clear enough. As the tammar population increased, fox baiting would be reduced, with the result that more foxes would be in place to pick off the wallabies: as the tammar population fell away, fox baiting would be intensified, and the wallaby population would then be able to increase and spread further. The distribution of the tammars could thus be effectively regulated through the manipulation of fox numbers: the farmers' long-established pest could be deployed in order to keep control over a potential one. This would be all the more effective, evidently enough, if farmers who were resident on the physical boundary between national park and agricultural land cooperated with the conservation scientists and the park rangers who would implement the science on the ground. A number of additional variables that might affect the rate of wallaby expansion beyond Innes National Park were factored into the scientific modelling. Again, however, the general point being made was that the local population's fears of an uncontrolled and destructive invasion of their grain fields were found to be at odds with the scientific evidence.

As is usually the case with such documents, the draft proposal was meticulously presented and systematically argued. The most likely counterarguments concerning the possibilities of risk and threat from the relocation project were anticipated and headed off by the welter of scientific discourse. It was a very thorough presentation, which was precisely what made all the more conspicuous the document's imbalances; the proposal ran to 66 printed pages, but only two of these were given over to 'Social and economic considerations'. What merits emphasis is that this kind of imbalance reflected the modus vivendi of the wider institutional body of the DEH. In addition to the practice of natural science being the everyday business of the $\mathrm{DEH}$, its leadership was devoted to spreading its commitment to a pervasive scientism among the general public. Inasmuch as it did this with fervour and zeal, any kind of critical response from below that was not conspicuously informed by the culture of natural science was given short shrift, or remorselessly contested by yet another body of scientific evidence. 


\section{The view from below}

The local people who made up the frontline of opposition to the relocation proposal were, in contrast, deeply imbued with the culture of rural life that predominated throughout Yorke Peninsula. They were long established, moderately well off and organised in such a way as to maximise the profitability of the family farm, and the codes of self-help and self-reliance were ones that fully informed the practice of their everyday life. The only consideration to qualify the emphasis on family self-reliance was a sense of responsibility to the wider community, but there was never much prospect that the integrity of the former might be compromised by the demands of the latter, which was regularly translated into such contributions as membership of the community fire service, the township association and representing the region in agricultural, fishing, commercial and sports organisations. To be known simply as a good neighbour or stalwart community member was quite sufficient public recognition for most people.

Well before the relocation project was imposed on the community at Innes and its environs, the DEH, in contrast, was considered a poor neighbour with little regard for the collective interests of local folk. The Parks and Wildlife Service, the branch of the department responsible for its national parks, was widely considered deleterious in the maintenance of the Innes National Park boundary: it failed to prevent invasive weeds from spreading to the surrounding farmland or to curb the movement of large wildlife from park terrain into land under wheat and barley. One subject of constant complaint was the rising population of kangaroos that thrived in the national park while regularly feeding outside its limits. Another was that Parks and Wildlife officers were too reliant on the 'book learning' acquired at city-based colleges and were loathe to augment the formal information they had with local knowledge hard won through extracting a living from the soil.

Above all other differences, though, it was the dispute about the part to be played by fox predation in controlling wallaby numbers that symbolised the cultural divide between the conservation scientists and the region's farmers. For while the scientists were assured and confident about their ability to manipulate the fox population, the farmers scoffed at such inflated and hubristic claims, and counterpoised against them their own local knowledge and commonsense.

The fox problem was undoubtedly a major one for all farmers in this area who combined the production of grain with raising cattle and sheep. They spoke uncompromisingly about the toll that fox predation took annually. It was, however, generally taken to be 'a fact of life' that could never be greatly changed but rather had to be rendered tolerable or manageable. If a farmer believed that the fox problem was out of control on his land and adjacent properties, a handful 
of young men would go out spotlighting for a few nights and kill several score - more if the effort and expense were felt to be worthwhile. A 'big hit', which combined intense baiting and shooting, was usually organised in the weeks before the lambing season, and for a while fox sightings would be negligible. It was, however, still recognised that throughout the year the fox problem was one to be lived with instead of somehow resolved.

It was to be expected, then, that farmers and their dependents were generally sceptical when the conservation scientists from the city or park rangers at Innes claimed that the fox population could be carefully modulated, and even that this could be represented diagrammatically. The cleverness and conceit thus being displayed were symptomatic of the cultural divide that local people had encountered in previous circumstances when city-based bureaucrats steeped in 'book learning' attempted to impose their schemes at the rural periphery.

I emphasise here that the local men and women at the forefront of opposition were well versed in the interpretation of tables, charts and the texts of documents from government sources. As representatives of the local community on a range of regional committees and boards, they were used to perusing and picking up on policy details that would impact on them most. Their critique of the Draft Translocation Proposal was no knee-jerk reaction. Further, they clearly acknowledged that one of their major problems was that the full impact of the wallabies' return to the mainland would not be felt for several years, even decades; no one, themselves included, could accurately predict such a distant prospect. In this light, there was one section of the proposal that especially concerned them. For the foreseeable future, the reintroduced tammar would be classified as an 'endangered species' and therefore protected by law from any kind of aggressive response from local farmers and others. In the draft proposal, however, it was acknowledged that where the tammar population was not effectively controlled by fox predation as scientifically predicted, permits might be issued 'to reduce tammar abundance'. This would, however, be allowed only where their adverse impact on farmers' valuable crops had been clearly established. This open admission was taken to epitomise the indifference of the $\mathrm{DEH}$ and its scientists to the circumstances of local agriculturalists. In addition to it here being acknowledged that 'tammar abundance' was a real possibility, the wallabies would have to seriously impact on local crops before the farmers could legally cull them.

Opposition to the project drew on much more than local knowledge specific to production on the peninsula and the problem with foxes. It drew also on regional knowledge relating to the disastrous environmental situation prevailing on Kangaroo Island, a mere 60 kilometres to the south-east and across Investigator Strait. On this island, a different but closely related species of tammar wallaby had long ago attained pest status; especially for farmers with agricultural land 
proximate to the island's national parks, the economic consequences were dire. Not only had successive state governments failed to tackle the tammar problem, the island's koala population had expanded to the point at which eucalypt stocks were exhausted and, despite a considerable body of scientific research that called for a severe reduction in koala numbers, no serious government response had ensued for fear of adverse publicity that might impact on the profitable tourist trade from Japan (see, for example, Lunney and Mathews 1997; Stratford et al. 1999).

In the estimation of the farmers closest to Innes National Park, there was a real prospect of the relocated tammar wallabies likewise becoming a significant pest, but then being protected by the 'cute and pretty' image that, before too long, would be traded on by the tourist industry. In order to explore these evident parallels and turn them to political advantage, the most vocal critic of the proposal, a middle-aged farmer resident in Warooka, spent a few days on Kangaroo Island making a video in which several beleaguered landowners and their wives detailed their travails, ranging from the loss of valuable sweet crops (lucerne, lupins and cereals) through to the gruesome task of shooting the tammar pest in large numbers. Armed with his home video, the farmer then arranged a public meeting at Warooka (the main settlement closest to Innes National Park) under the auspices of the South Australian Farmers' Federation in order to mobilise public support for the cause. Some 55 members turned up, evidently representing a substantial proportion of agriculturalists in the area. The response to several motions from the floor indicated the depth of regional support for concerted opposition to the relocation project. At much the same time, letters to regional newspapers and The Stock Journal signalled much the same strength and depth of community opinion.

From late 2003 and throughout 2004, the local folk who had taken the lead from the outset maintained their strident public opposition, but at the same time they had little option but to be drawn into the bureaucratic process of cooptation that the rituals of community consultation were designed to effect. The rituals of consultation are precisely that in situations in which the incomparable resources of the modern State are arraigned against a numerically insignificant grassroots population. Unless they are able to mount a substantial and well-resourced grassroots movement that can not only seriously contest but present viable alternatives to proposals emanating from state institutions, local populations are relatively powerless in these modern times. Ordinary folk have little alternative but to accept the rhetoric, engage with the mechanics of democratic consultation and thereby work for minor changes that necessarily leave the significant parameters of any proposal intact. Faced with the overwhelming resources of the DEH and the unqualified commitment to the project from the government in power, the grassroots network had no option but to try to wrest whatever they could from the consultative committee. 
In the event, their success on this score was negligible, despite the enormous energy and time they invested in it. The main demand they put forward was the provision by the State of financial compensation should the tammar wallaby population take off and invade the grain fields belonging to themselves and their neighbours, a threat that might eventuate only in the long-term but nevertheless had to be prepared for. Particularly in the light of what had happened on Kangaroo Island and elsewhere in the country where wallaby populations had run out of control, and since various government bodies had proved quite incapable of dealing with such situations, an appropriate compensation scheme became their main concern. The response from above to this and related issues, however, was emphatically negative. The representatives from $\mathrm{DEH}$ on the consultative committee were adamant from the outset that any question of compensation arrangements lay well outside the committee's brief. Nor was there any mechanism in place for the issue to be raised at higher levels. In light of this recalcitrance, a delegation of Innes farmers eventually forced a meeting with the head of the DEH. He did no more, however, than reinforce the blanket refusal with which the proposal had been received lower down the institutional hierarchy. He was adamant that neither the DEH nor the government to which it was responsible would have a bar of compensation arrangements that would establish a precedent with far-reaching consequences for many other spheres of economic life.

\section{Conclusion}

It was to be expected, then, that a forced engagement with the rituals of community consultation eventually reinforced local people's view of the DEH and the politicians behind it as distanced, arrogant and uncompromising. At best, the consultation process was considered a waste of time and effort; at worst, it was a sham and a deceit.

The most significant outcome of this intense and protracted politicking was that when the first batch of tammar wallabies was finally released inside the park, the farm families who had a boundary with it were as hostile as ever to the project. Further afield, it was regarded with circumspection and concern for the long-term consequences. Subsequently, when the rangers put on a small celebration to signal the achievement of the tammar relocation inside the national park, the still stridently opposed farmers and their families were conspicuous by their absence. This stand-off meant that precisely the local folk who could have been of most use to the project were the ones most alienated from it. In no sense was this a fatal setback to the overall project. It will be recalled, however, that the close cooperation of neighbouring farmers, wherever the tammar wallabies were to be introduced, was written into the proposal from the outset as a highly desirable, if not imperative, requirement if the exercise was to be given the best chance of success. 
The point that has to be reinforced at this juncture is that the tammar wallaby relocation scheme was, from the outset, an important and innovative prospect. For the dedicated team of conservation scientists, it was a major challenge to their scientific professionalism and one from which they could gain extensive and unique experience. For the upper echelons of the DEH, the project held out a good deal of prestige and publicity in that the return of extinct wildlife to its original wilderness would create an extremely favourable public image. For the state's politicians, especially the Minister for the Environment and the Premier, the return of the tammars could be presented as a highly symbolic contribution to the preservation of Australia's biodiversity, and therefore well indicative of the state government's increasingly important environmental credentials.

Inasmuch as it seems likely that the preservation and enhancement of biodiversity on the Australian continent are going to be central to the way in which rural futures are thought about, there are some salutary lessons to be gleaned from this case study. The first is that a range of social and cultural considerations can influence, if not determine, how grassroots populations respond to initiatives from above - and by no means are these entirely dependent on the intrinsic significance of the policy or proposal. The people of lower Yorke Peninsula had no problems with the overall goal of preserving and enhancing their region's biodiversity, and thus contributing to the national scene. As with so many other rural occupations, the region's agriculturalists considered themselves true environmentalists whose credentials easily outstripped the membership of any city-based green group. These same local folk were, however, frequently cautious, circumspect and pessimistic when external institutions bore down on them with preconceived policies and programs that would impact on their rural way of life. And the more external agencies supplemented their arguments in the same discursive terms with which they began, the more intransigent local people were likely to become.

Circumspection and suspicion about the motives of government institutions and their associated agencies are in no sense restricted to the people of lower Yorke Peninsula. They are considered judgments that are commonplace in the cultures of rural Australia, which is why any official policy or program for the rural future ignores them at their peril. It is not appropriate, therefore, for a major institution such as the DEH to approach 'social and economic considerations' as if they are of secondary or minor consequence, for the straightforward reason that to do so stores up further problems for the future rather than according them proper consideration from the outset. To many people, and certainly to an anthropological audience, this point might be self-evident. As I hope is evident from the above account, however, that was by no means the case with the tammar relocation project, and although the consequences were not disastrous, they would assuredly have been best avoided, if at all possible. 
The second cautionary point is that institutions such as departments of the environment cannot be left to determine on their own account the extent and the degree of community involvement in such major areas as the protection and advancement of biodiversity, for their institutionalised scientism means that they respond with outright indifference or heavily qualified attention to non-scientific knowledge claims. Broadly speaking, departments of the environment approach community consultation as a problem to be dealt with and, if necessary, to be circumvented altogether, rather than the source of an alternative, valid and relevant body of knowledge. They function as if their stock definition and body of knowledge are the only ones to be consistently prioritised, yet this occurs at precisely the time at which more and more people in societies such as Australia become increasingly aware of the limitations of natural science and the wide-ranging problems that a previously uncritical dependence on it has generated and compounded. Circumspection towards science, and cynicism towards institutions that privilege it as a source of knowledge above all others, are by no means restricted to the local population of lower Yorke Peninsula. They are significant political developments in Australian society at large, and therefore ones that departments of the environment ignore at their peril.

The third point is that, notwithstanding points one and two, as an anthropologist, I am less convinced than most that continuing dialogue and exchange of views between conservation scientists and local populations are the ways in which differences can be resolved and productive ways forward generated. In the comparative literature, mainly drawn from experience in the United States, where the aims of conservation science and the concerns of local landowners have come into open conflict, sociological analysis generally concludes that the different parties have to continue their dialogue, they have to persist with their continuing exchange of views, and so eventually arrive at a working compromise (for example, James 2002; Norton 2000; Peterson and Horton 1995; Wondolleck and Yaffee 2000).

The main problem with this kind of conclusion is that it fails to address the uneven distribution of power, which not only characterises such relations, it generates the conflict between them in the first place. An emphasis on continuing dialogue and exchange of ideas infers a degree of equivalence and equality between partners to the conversation that is, in reality, quite mythical. In the South Australian case, as in comparable others, the discourse of conservation science was informed and backed by an institutional and political structure of enormous influence and power. Whatever the credibility and legitimacy of those who opposed the tammar relocation project from below, the conservation scientists from the DEH had only to persevere with their major ambitions in order to finally realise them. This is, more or less, the current situation. The project was somewhat delayed by local community opposition, a number of 
costs were incurred that would otherwise not have materialised and the local support from farm families that would have been far preferable was not forthcoming. None of these costs, however, was overwhelming for the elementary reason that institutional resources provisioned by the State far outweighed anything that the local opposition could possibly muster. As Australia's rural future becomes increasingly linked to major environmental goals such as the preservation of biodiversity and therefore the politics of conservation science, a major requirement will be how to accord proper recognition and authority to those who privilege and build on non-institutionalised, even commonsensical, bodies of knowledge and the folk discourse that gives public voice to them.

\section{Bibliography}

James, S. M. 2002, 'Bridging the gap between private landowners and conservationists', Conservation Biology, vol. 16, no. 1, pp. 269-71.

Lunney, D. and Mathews, A. 1997, 'The changing roles of state and local government in fauna conservation outside nature reserves: a case study of koalas in New South Wales', in P. Hale and D. Lamb (eds), Conservation Outside Nature Reserves, Centre for Conservation Biology, University of Queensland, Brisbane, pp. 97-106.

Maxwell, S. et al. 1996, Action Plan for Australian Marsupials and Monotremes, Australian Marsupial and Monotreme Specialist Group and IUCN Species Survival Commission, Wildlife Australia, Canberra, Australian Capital Territory.

Norton, D. A. 2000, 'Conservation biology and private land: shifting the focus', Conservation Biology, vol. 14, pp. 1221-3.

Peace, A. 1996, "'Loggers are environmentalists too": towards an ethnography of environmental dispute, rural New South Wales 1994-1995', The Australian Journal of Anthropology, vol. 7, no. 1, pp. 43-60.

Peace, A. 1999, 'Anatomy of a blockade: towards an ethnography of environmental dispute (Part 2), rural New South Wales 1996', The Australian Journal of Anthropology, vol. 1, no. 2, pp. 144-62.

Peterson, T. R. and Horton, C. C. 1995, 'Rooted in the soil: how understanding the perspectives of landowners can enhance the management of environmental disputes', The Quarterly Journal of Speech, vol. 81, pp. 139-66.

Poole, W. E. et al. 1991, 'Distribution of the tammar, Macropus eugenii, and the relationships of populations as determined by cranial morphometrics', Wildlife Research, vol. 18, pp. 625-39.

Recher, H. F. 1994, 'Why conservation biology: an Australian perspective', in C. Moritz and J. Kikkawa (eds), Conservation Biology in Australia and 
Oceania, Surrey Beatty and Sons, Chipping Norton, New South Wales, pp. $1-15$.

Stratford, E. et al. 1999, 'Managing the koala problem: interdisciplinary perspectives', Conservation Biology, vol. 14, no. 3, pp. 610-18.

Taylor, A. C. and Cooper, D. W. 1999, 'Microsatellites identify introduced New Zealand tammar wallabies (Macropus eugenii) as an "extinct" taxon", Animal Conservation, vol. 2, pp. 41-9.

Taylor, A. C., Sunnocks, P. and Cooper, D. W. 1999, 'Retention of reproductive barriers and ecological difference between two introduced sympatic Macropus spp. in New Zealand', Animal Conservation, vol. 2, pp. 195-202.

Wondolleck, J. M. and Yaffee, S. L. 2000, Making Collaboration Work, Island Press, Washington, DC.

Yaffee, S. L. and Wondolleck, M. 2000, 'Making collaborations work', Conservation Biology in Practice, vol. 1, pp. 15-25. 